\title{
Client Satisfaction and Health Services Delivery in an African Public Clinics: The Case of Mutare, Zimbabwe
}

\author{
Wehnam Peter Dabale ${ }^{1, *}$, Nelson Jagero ${ }^{2} \&$ Lauraine Mariane Nyatoti ${ }^{3}$ \\ ${ }^{1}$ Alumni Affairs Directorate, Africa University, P. O Box 1320 Mutare, Zimbabwe \\ ${ }^{2}$ Faculty of Human Development and Education, Chuka University, P.O BOX 109 Chuka, Kenya \\ ${ }^{3}$ Faculty of Management and Administration, Africa University, P. O Box 1320 Mutare, Zimbabwe \\ *Corresponding author: Alumni Affairs Directorate, Africa University, P. O Box 1320 Mutare, Zimbabwe. E-mail: \\ dabalew@africau.edu
}

Received: September 29, 2014

Accepted: February 3, $2015 \quad$ Online Published: April 15, 2015

doi:10.5430/mos.v2n2p68

URL: http://dx.doi.org/10.5430/mos.v2n2p68

\begin{abstract}
The level of satisfaction that clients experienced having used a service and the quality of the service delivery is a key to maintaining good relationships and growing successful business; hence the objective of this study was to explore the level of satisfaction of outpatients with the services deliveries in African Public Clinics. Correlational research design was used in the study; a total of three hundred and twenty six respondents were used to collect data using questionnaires and descriptive statistics was used to analyze the data. Findings indicated that, there is a relationship between health service delivery and patient's satisfaction. Recommendations included improve quality of health care services, continuing surveys on patients and education campaigns to foster community awareness and understanding of health services, develop a sense of ownership thereof, and encourage positive participation.
\end{abstract}

Keywords: client satisfaction; health services delivery and public clinics

\section{Introduction}

A national economy's development is commonly determined by the well being of its citizens, as the quality of life entails an increase in a nation's productivity. There was easy implementation of development programmes to improve the quality of life of the people in a nation with healthy population. The good health of nations is vital to human development and economic growth and it is important to analyze health systems performance and to share what is known with local stakeholders and the international community (Brundtland, 2001). The importance of quality health has facilitated the adoption of a number of human rights provision level to protect and enhance the basic needs of human kind including the right to adequate and quality health care during sickness.

Developing countries have increasingly developed their healthcare services in response to clients needs over decades. Studies done on clients' (patients) satisfaction revealed that phenomenon; that satisfied clients have never been standard and straightforward, it went on to suggest that satisfaction can either be subjective and individualized; as well as a perception by the individual on the receiving end.

In Zimbabwe for instance, key performance indicators are used to monitor and evaluate the effectiveness and efficiencies of health institutions and their staff (MoHCW, Zimbabwe 2010 - 2012). Zimbabwe being ranked as the second-most developed countries within the Southern African Development Community (Munjanja, 2007) had provided a great inroads in providing decent health care to the general population, and the combined effort from the Ministry of Health and Child Welfare and its partners to reduce the prevalence rates for various diseases including malaria, tuberculosis and HIV/AIDs was especially noteworthy.

However, more efforts are needed to stabilize the Health services delivery system; more specifically the quality of care which will indicate the quality of service of the providers as perceived by the patients regarding various factors. Members of the public, prospective consumers of healthcare and stakeholders in general have often commented that a healthcare organisation is rated by the quality of services rendered; therefore, investigating the patients' perceptions of services received at the outpatients' department of public clinics in Mutare, was an attempt to determine the 
relationship between the clientele expectations and services rendered.

\subsection{Statement of Problem}

There is an emergent revolution in the healthcare industry in recent years and the industry had tremendous restructuring in its services delivery, which was an attempt to survive the trends coupled with globalization and competition. The majority health care clients in Zimbabwe prefer to utilize private health care services such as private laboratory, private drug stores, which they claimed to be providing a better quality of medical care, highly effective treatment and good user-provider interaction. Consequently, there are also a growing number of private healthcare givers in the country. This study therefore, was meant to explore the client satisfaction and health delivery services in public clinics in Mutare, Zimbabwe; more specifically it was to determine the relationship between quality care, treatment and satisfaction of clientele.

\section{Literature Review}

\subsection{Empirical Studies}

Clients satisfaction and service quality is becoming a critical objective in the strategic planning process as it is attributed to the development of high technology clientele who are more informed (Ramsaran-Fowdar, 2008). To provide high-quality care, providers must understand and respect their clients' needs, attitudes, and concerns. These client perceptions are in turn affected by personal, social, and cultural factors. Research highlighted the benefits of addressing client perspectives on quality of care, since it leads to improved client satisfaction, continued and sustained use of services, and improved health outcomes (Kols \& Sherman, 1998).

Although there seems to be a consensus in the literature that customer satisfaction and service quality are separate and unique constructs, their distinctions in definition and conceptualization still exist (Choi, Cho, Lee, Lee \& Kim, 2004). The two constructs seem to have many similar characteristics, but they are distinct and evaluated in different ways (Vinegre and Neves, 2008). First the evaluation of satisfaction is based on customer's experience of a specific service, and perceived service quality is not necessarily experience based (Cronin, Brady \& Hult, 2000). Service quality lasts longer than satisfaction because satisfaction is a reflection of only one's specific transaction or service experience (Martinez, 2001).

Furthermore, other scholars such as Zeithml (2000) proposed that service quality evaluation of a product or a service encounter leads to an emotive satisfaction assessment that in turn drives behavioural intention while Cronin et al, (2000) argued that service quality is a cognitive construct whereas satisfaction is an affective construct. This thus means that service quality is an antecedent of satisfaction. Some other empirical studies in health care quality supported this casual link between patient's perception of health quality and satisfaction as proposed by Choi et al, (2004).

Scotti, Harmon \& Behson (2007) investigated how a high performance work system and customer orientation influence employee and customer perceptions of service quality and patient satisfaction in ambulatory health care centres. Their study supported the argument that perceived service quality is one of the determinants of patient satisfaction.

A customer service satisfaction survey done in the City of Johannesburg by the Department of Health (2004), they recommended that patients should not be left unattended due to facility problems and health care services should be accessible and available when needed. Similarly, van Charante, et. al., (2006), carried out the evaluation of patient satisfaction with Primary Health Care (PHC) and quality of health care and they found that accessibility and continuation of health services, waiting time, consultation of patients by health care providers, availability of medicines, performance of doctors and nurses, laboratory investigations and level of privacy in the consultation rooms are dynamics in health care services and should be maintained at all times to enhance patients' dignity.

However in a related study of gender and patients satisfaction Weisman, et al (2000) found that women in terms of visits, were mostly satisfied with the information and the continuity of care, whilst men' overall satisfaction depended mostly on individual attention they got from staff. The Batho Pele Principles (a South African political initiative for better delivery of goods and services to the public) measured patients' satisfaction as accessibility of health care services provided, ensuring courtesy, considering patients as unique individuals, adequate health information to patients, being able to answer questions asked by patients politely, redressing the wrongs with a positive attitude (Department of Public Service and Administration 1997).

Target Research (2001) carried out a survey to investigate the image of the Avenues Clinic in Harare, Zimbabwe and their findings revealed that nursing care was the first of the three main attributes that clients value in a hospital. The 
other attributes following nursing were good quality equipment and affordability. We can therefore assume that patients receiving a certain standard of nursing care will be satisfied and will be likely to return for the same service or recommend the service to family or friends hence market the public clinics service quality and a focus on acceptable standards have received a lot of attention both at national level and organizational level. The Ministry of Health and Child Welfare (MoHCW) for Zimbabwe approved a national health budget strategy. The strategy was meant, among other things, to address the quality of services with a special emphasis on outcome hence attaining patient satisfaction.

\subsection{Theoretical Framework}

The theoretical framework adapted for this study was the behavioural model of model of health service use as propounded by Aday and Andersen (1978) to determine the relationship between client satisfaction and the service delivery. This model was based on the organization of an array of correlates of health and healthcare behaviour from different literature in sociology, psychology, economics and medicine into predisposing, enabling and need predictors of families' use of health system model for construction of conceptual framework.

The purpose of utilising this model was to help construct a questionnaire with a good reliability and to secure a high degree of validity, which means that the questionnaire used had a strong internal consistency and was constructed to measure what it was supposed to measure.

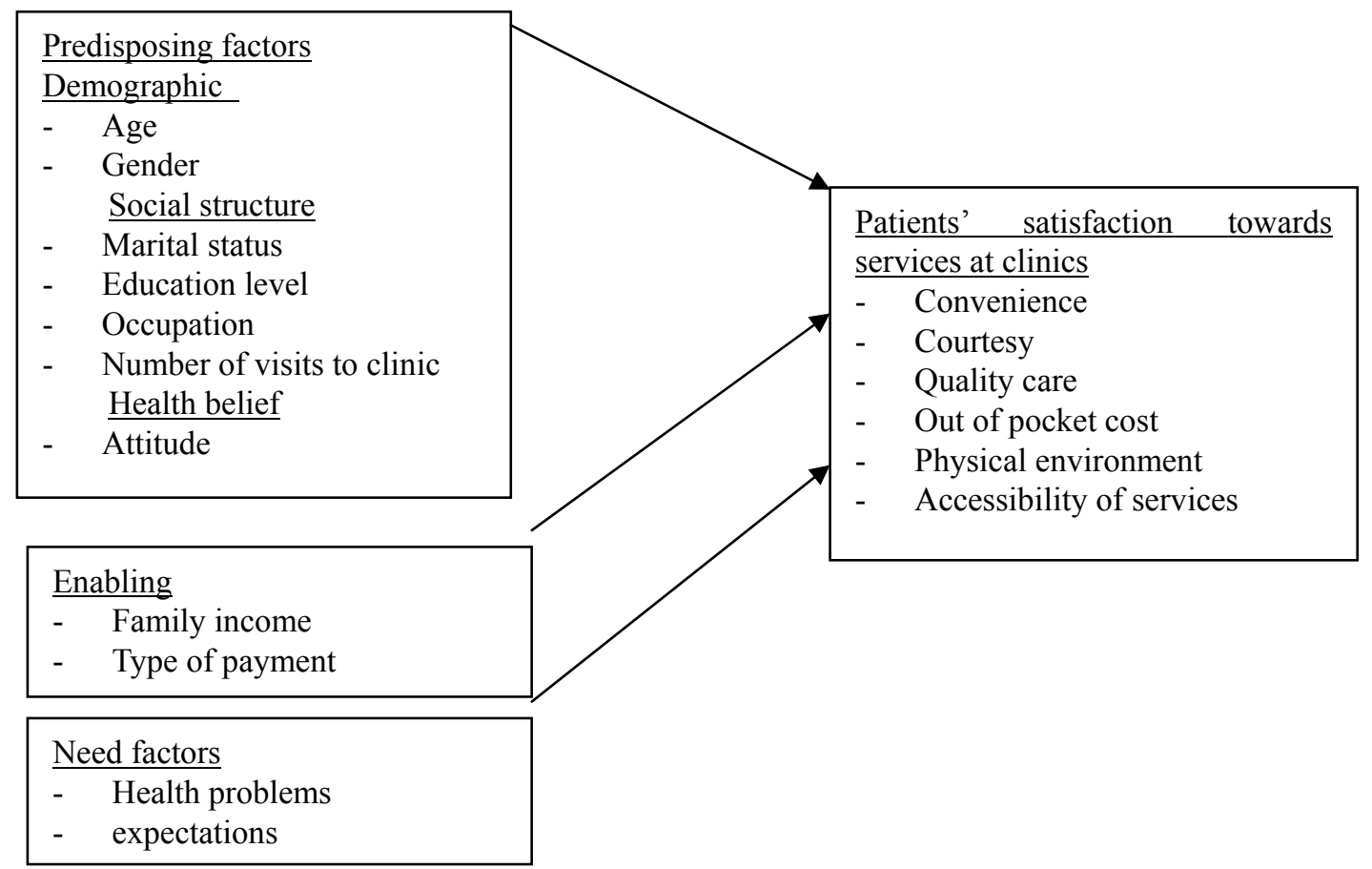

Figure 1. Conceptual Framework Using Aday and Andersen's Health Symbol Model

\section{Methodology}

\subsection{Research Design}

According to Babbie and Mouton (2001), a design serves as the blue print that indicates how the investigation is expected to be carried out. Correlational research design was used in this study with an attempt describe and measure the degree of association (or relationship) between the dependent variable (client satisfaction) $\mathrm{X}_{2}$ and the independent variable (service delivery) $\mathrm{X}_{1}$ according to the following equation:

$$
\mathrm{X}_{2}=\mathrm{a}+\mathrm{bX}_{1}
$$

Where $\quad \mathrm{X}_{2}=$ Client satisfaction

$$
\begin{aligned}
\mathrm{X}_{1} & =\text { Service delivery } \\
\mathrm{a} & =\text { Constant }
\end{aligned}
$$




\subsection{Data Analysis}

Data collected for the study was coded and analysed using the statistical package for social sciences (SPSS). Quantitative techniques used included both descriptive and inferential statistics. Descriptive statistics used included mean and inferential statistics used were Pearson Correlation, Analysis of Variance (ANOVA) and Simple regression. The advantage of using these inferential statistics was that, they permit the researchers to analyze relationships among a number of variables in a single study (Gall and Borg, 1996).

\section{Findings and Discussions}

\subsection{Descriptive Statistics}

Table 1. Model Summary

\begin{tabular}{ccccc}
\hline Model & $\mathbf{R}$ & $\mathbf{R}^{2}$ & Adjusted $\mathbf{R}^{\mathbf{2}}$ & Standard Error \\
\hline 1 & .581 & .338 & .336 & .96604 \\
\hline
\end{tabular}

Predictors: Services delivered $\mathrm{X}_{1}$

Dependant Variable: Client Satisfaction $\mathrm{X}_{2}$

In table 1, the multiple $\mathrm{R}$ is a correlation between the dependent variable (client satisfaction) and the independent variable (services delivered). It can be seen from the table that the correlation between the dependent variable and the independent variable was as low as 0.581 .

The multiple $\mathrm{R}$ square $\left(\mathrm{R}^{2}\right)$ is the proportion of variance in the dependent variable associated with variance in the dependent variables. This proportion is a good indicator of the explanatory power of the regression model. Therefore, from the table $1, \mathrm{R}^{2}$ is 0.338 . This shows that the dependent variable $\mathrm{X}_{2}$ (client satisfaction), according to the model summary is $33.8 \%$ affected by the independent variable $X_{1}$ (services delivery). The other $62.2 \%$ of the factors absent from the model summary could have been from the participant's different characteristic such as age, level of education and their previous experiences with service providers.

Table 2. Regression Coefficient

\begin{tabular}{cccccc}
\hline Model & $\begin{array}{c}\text { Unstandardized } \\
\text { Coefficient Beta }\end{array}$ & $\begin{array}{c}\text { Standard } \\
\text { Error }\end{array}$ & $\begin{array}{c}\text { Standardized } \\
\text { Coefficient Beta }\end{array}$ & t & Sig \\
\hline Constant (a) & 1.447 & 0.186 & - & 7.800 & 0.000 \\
Services $\left(\mathrm{X}_{1}\right)$ & 0.600 & 0.048 & 0.581 & 12.413 & 0.000 \\
\hline
\end{tabular}

Predictors: Services delivered $\mathrm{X}_{1}$

Dependant Variable: Client satisfaction $\mathrm{X}_{2}$

The model from the table 2 can be expressed as follows:

$$
\mathrm{X}_{2}(\text { satisfaction })=1.447+0.186 \mathrm{X}_{1}
$$

The beta column indicates the value of standardized regression coefficient. Beta represents the effect that standard deviation difference in the independent variable would have on the dependent variable in standard deviation (the standardized scores of the dependent variable).

Therefore from the regression analysis the unstandardized beta when $\mathrm{X}_{1}$ (services) was regressed against $\mathrm{X}_{2}$ (satisfaction) was 0.600 with $t$ value of 12.413 which was far greater than 2.00 and a significance of $0.000(<0.005)$. This shows that $X_{1}$ is a major predicator of $X_{2}$. This could be interpreted that a ten percent (10\%) increase in services delivery in public clinics will increase clientele satisfaction by sixty percent $(60 \%)$.

\section{Conclusion}

Our result suggested that there is a relationship between the client satisfaction and the services delivery. It was further observed that the public clinics in Mutare were offering quality care and treatment which is satisfying their clients and some of the services rendered by the health personnel (nurses, receptionists, and pharmacy staff) were appreciated by the clientele. However, other factors which are not part of the study and would have effect on the client's satisfaction could have been from the client's different characteristic; such as age, level of education and their previous experiences with other service providers.

Our study therefore, suggests three recommendations for stakeholders and three recommendations for future research. 
Firstly, the public clinics should continue to provide quality care and treatment to its clientele for them to remain competitive. Secondly, surveys on patients should also be done regularly so as to assess the level of service provision as well as the satisfaction of the clients and thirdly, there should also be education campaigns to foster community awareness and understanding of health services, develop a sense of ownership thereof, and encourage positive participation.

On future research, our study focused on only services delivery to only the clients and the public health clinic, whereas views of the services provides, private and community health care could not be captured which affected the result to some extend theretofore, future study could consider the relationship between patients' satisfaction with health care services provided at Community Health Centre's (CHCs); Health professionals' perceptions of health care services provided at clinics and Professional nurses' perceptions of clinic patients' health care service needs.

\section{References}

Aday, L. A., \& Andersen, R. (1978). Theoretical and methodology issue in sociology: Study of satisfaction with medical care. Soc Sci Med, 1(2), 28.

Babbie, E., \& Mouton, J. (2001). The Practice of Social Research. Oxford: University Oxford Press.

Brundtland, G. H. (2001). Improving health systems' performance. OECD, p.4.

Choi, K., Cho, W., Lee, S., Lee, H., \& Kim, C. (2004). The relationships among quality, value, satisfaction and behavioral intention in health care provider choice: A South Korean study. Journal of Business Research, 57, 913-921. http://dx.doi.org/10.1016/S0148-2963 (02)00293-X

Cresswel, J. W. (1994). Research Design: Qualitative and Quantitative Approaches. Thousand Oaks California: Sage Publications.

Cronin, J. J., Brady, M. K., \& Hult, G. T. M. (2000). Assessing the effects of quality, value and customer satisfaction on consumer behavioral intentions in service environments, Journal of Retailing, 76(2), 193-218. http://dx.doi.org/10.1016/S0022-4359 (00)00028-2

Gall, M., \& Borg, M. (1996). Education Research: An Introduction. New York: Longman.

Munjanja, S. P. (2009). Ministry of Health and Child Welfare, Zimbabwe: Maternal and Perinatal Mortality Study 2007. Retrieved 201/04/14 from http://www.unicef.org/zimbabwe/ZMPMS_report.pdf

Ramsaran-Fowdar, R. R. (2008). The relative importance of service dimensions in a healthcare setting. International Journal of Health Care Quality Assurance, 21(1), 104-124. http://dx.doi.org/10.1108/09526860810841192

Scotti, D. J., Harmon, J., \& Behson, S. J. (2007). Links among high - performance work environment, service quality, and customer satisfaction: An extension to the healthcare Sector. Journal of Healthcare Management, 52(2), 109-24.

Target Research. (2001). Image of the Avenues Clinic amongst medical service providers, patients, potential patients and employees. (Unpublished research).

Zeithaml, V. A. (2000). Service quality, profitability, and the economic worth of customers: What we know and what we need to learn. Journal of the Academy of Marketing Science, 28(1), 67-85. http://dx.doi.org/10.1177/0092070300281007 